\section{UK citations}

SIR-In view of the publicity given to the perceived decline of British basic science (see for example the leading article 'British science over the hill', Nature 323, 655; 1986) the recently published list of the most-cited 1984 life sciences articles from the Institute of Scientific Information in Philadelphia (Current Contents, Life Sciences, 29, No. 49, 3-17; 1986) is of interest.

Of the 102 most-cited papers, Dr Eugene Garfield has found that 61 of the institutions in which the research work was carried out are located in the United States and 13 are in the United Kingdom. Countries with which the United Kingdom has recently been unfavourably compared in fact produce relatively fewer scientific papers in this immediate highimpact' category; only seven of the institutions are in France, four in Japan and one in West Germany.

The comparatively strong presence of the United Kingdom in this latest record of trends in the life sciences seems not merely attributable to excellence in one or two areas, as the highly cited British papers covered very different topics such as growth factors and oncogenes, intracellular messengers, ion channels and secretion, transition metals in disease, antibodies in AIDS, renal transplantation, human complement genes and leishmaniasis. In view of the recent attacks on the British university system, it may also be worth pointing out that most of the highly cited UK papers came from research groups working in universities.

O.H. Petersen

Department of Physiology,

University of Liverpool,

PO Box 147,

Liverpool L69 $3 B X, U k$

\section{On the defence}

SIR-I have a certain sympathy for Alvin Weinberg's preference (Nature 324, 610; 1986) for a "defence-dominated" regime with vastly reduced nuclear arsenals. But I am not optimistic about its ultimate feasibility, as more than just scientific questions are involved. The United States and the Soviet Union would also have to trust each other enough to agree to release each other from the mutual hostage relationship of nuclear deterrence.

The Reagan administration's current unilateral and aggressive pursuit of strategic defences - the Strategic Defense Initiative (SDI) - seems almost designed to prevent this. The Soviets clearly view SDI as an attempt by the United States to achieve a first-strike capability and will redouble their efforts to maintain their deterrent force, they are hardly likely to respond by reducing their nuclear arsenals. A defence-dominated world cannot be imposed unilaterally but can arise only through mutual agreement after a long process of disarmament and the development of some degree of trust among all the nuclear powers.

Weinberg may be right to complain that the Cornell survey of the National Academy of Sciences members' views on strategic defence failed to offer the possibility of a defence-dominated world. Taking these political considerations into account, however, I doubt whether many members of the academy would have given it high prospects.

Mark GoOdman Institute for Theoretical Physics,

University of California,

Santa Barbara, California 93106, USA

SIR-I read Alvin Weinberg's letter (Nature 324, 610; 1986) with care but find his argument for supporting the Strategic Defense Initiative (SDI) difficult to follow. He poses the question "... if arms control leads to a mutually agreed reduction in the offensive threat to, say, a few hundred offensive missiles, can a defensive system be effective against this much lower threat? The answer to this question is probably yes...." The essential word in this quotation is "if". Can one reasonably expect the Soviet Union to agree to reduction in missiles to a level that renders its offensive capacity negligible in the face of a deployed anti-missile system - in effect, unilaterally to disarm?

The Soviet Union is likely instead to seek parity, not in nuclear warheads or launchers, but in deliverable warheads. Thus any success in developing SDI by the United States will almost certainly be matched by an increase in nuclear missiles by the Soviet Union. It is true that this situation may be modified if the Soviet Union itself develops and deploys an antimissile system on the scale of SDI but the inevitable temptation then for the United States will surely be to increase its own weapons to ensure that it maintains what it considers to be an adequate deterrence.

The history of warfare has been a constant competition between offensive weapons and defensive systems with developments in one serving as a stimulus for the other. Why should we suppose that the response to SDI should be any different?

\section{West End,}

D.W. Mason

\section{Witney,}

Oxon $O X 86 \mathrm{NJ}, U K$

SIR-Alvin Weinberg's letter (Nature 324, $610 ; 1986)$, criticizing the Cornell Survey of the opinions of National Academy members of the Strategic Defense Initiative (SDI), has a basic flaw that invalidates his argument. His criticism is based on the expectation that SDI may be effective against an attack by a few hundred missiles rather than the several thousand now possessed by each side and that missile reduction should therefore be sought. Weinberg proposes that critics of SDI should work towards such a reduction and for SDI as a means of stabilizing arms reduction.

The Reykjavik meeting brings out the inconsistencies of Weinberg's argument. The prospect of a substantial missile reduction collapsed over Soviet concern with SDI. That concern is probably based on Weinberg's thesis that SDI will be effective against the reduced missile threat rather than the present Soviet missile force so that a large reduction would leave the Soviet Union at a serious disadvantage.

A second thesis for Soviet concern would be an inability to respond to a US first strike. To many of us, such an action may not seem likely, but the situation could appear different to Soviet leaders. The repeated pronouncements of US presidents, from Truman on, on the use of nuclear weapons, and the repeated rejection by the United States of a 'no first strike' policy, would make the Soviet Union oppose an SDI programme that would prevent a Soviet response to a US attack.

Consequently, SDI and nuclear missile reduction are not incompatible, as Reykjavik demonstrated. Thus, Weinberg's criticism of the Cornell survey is not justified, and his questioning of the scientists motives is inappropriate.

\section{NASA/Goddard Space}

Flight Center,

Greenbelt,

Maryland 20771, USA

\section{Shades of 1968}

SIR-Under the headline "Shades of 1968?" (Nature 324, 500; 1986) one reads that "just why General de Gaulle's government took such fright... has never been crystal clear".

Some clarity may be provided by a slightly different statement of the facts.

The students did not protest against a "modest package of educational reforms". They were chanting slogans such as "l'imagination au pouvoir" a vague claim - although unreasonable - if ever there was one.

Then the whole country came to a stop when strikes paralysed industry, public services and the administration. Elections were called, a new government was formed and for the first time Edgar Faure took charge of the Ministry of Education. He then had a new law voted that led to what might appear as sweeping changes rather than "anodyne reform"

\section{ETIENNE EISENMANN}

\section{Transgene,}

16 rue Henri-Regnault,

92411 Courbevoie Cedex,

France 